\title{
TENNIS ELBOW
}

By W. S. TegneR, B.M., B.CH., F.R.C.P.

Director, Department of Physical Medicine, The London Hospital

Tennis elbow is a painful condition of the elbow and forearm. The pain originates in the extensor origin at the external epicondyle of the humerus. In golfer's elbow the pain originates in the internal epicondyle. The name tennis elbow was first given to the condition by Morris (1882) and in England the name has persisted. But in the United States and the continent of Europe the term epicondylitis is more commonly used.

Tennis elbow is a common condition and causes much discomfort. In 1957,80 patients suffering from this condition were seen in the Department of Physical Medicine of the London Hospital; of these, 49 were women and 31 men. Golfer's elbow is much less common. During the same year nine patients suffering from golfer's elbow were seen; of these, six were women and three were men. Of the sufferers from tennis elbow two attributed the trouble to tennis. None of those suffering from golfer's elbow attributed the trouble to golf. Nevertheless, in tennis clubs and golf clubs the conditions are frequently found. But the London Hospital figures show that games are not the commoner causes of the trouble and that the conditions are common in industrial areas where opportunities for golf and tennis are not widely available.

The patients complain that they developed a pain in the elbow and forearm on gripping or lifting. Often there is no definite history of a cause of the trouble. It just comes on. Sometimes, as in tennis players, there is a history of constant dorsiflexion of the wrist while gripping. In other patients there is a history of a knock or blow on the epicondyle. The pain is aggravated by activity and relieved by rest. It does not usually interfere with sleep. It is not incapacitating and patients often put up with the discomfort for long periods before seeking advice.

On inspection the arm appears normal. There is no swelling and no effusion into the elbow joint. In tennis elbow, if the patient is asked to grip one's own hand she experiences pain from the external epicondyle spreading down the extensor muscles to the wrist. This is because in the action of gripping the wrist extensors go into spasm to $\overrightarrow{\vec{\omega}}$ hold the wrist extended while the fingers grip. On pressing the external epicondyle the patient feels considerable pain. In golfer's elbow the pain is 3 . similar but spreads down the flexors from the w internal epicondyle which is tender on palpation. These are musculo-tendinous strains at the origins $c$ of the muscle groups. They may be due to con- $\omega$ tinued pull or to direct violence. Some authorities: have tried to subdivide tennis elbow into various types according to the exact site of the strain but these subdivisions bring in unnecessary complications and are not helpful.

The diagnosis of these conditions, depending on $\overrightarrow{0}$ the pain of gripping and the tender epicondyles, 왕 usually straightforward. But sometimes the dififo ferentiation from brachial neuralgia may have be made. In brachial neuralgia the pain may spread down the forearm, but as a rule it is not relieved by rest, as is that of tennis elbow; it is $\frac{\mathrm{D}}{\mathrm{O}}$ frequently worse at night which is not the case with $\stackrel{\circ}{\Rightarrow}$ tennis elbow, and the epicondyles are not especially tender. Radiological examination does not help in this condition for in tennis and golfer's elbows the $\mathrm{X}$-rays are normal.

The eventual prognosis is good. The condition usually resolves in a matter of months without: treatment. But in some rarer cases the trouble 3 . may persist as long as two years. The fact that $\delta$ tennis elbow gets better eventually by itself led to certain mistakes in the days before moderno methods of treatment became accepted and $>$ established. For a patient often became disheartened at the failure of the first treatment that $\bar{N}$ had been prescribed and changed her doctor, if the second doctor also failed the patient might $N$ then be tempted to consult the osteopath or other N unqualified practitioner whose first treatmento succeeded. Indeed, formerly I used to teach thato I liked to be the third doctor consulted in an obstinate case of tennis elbow, for the chances? were that the condition was now due to clear up spontaneously.

The history of the treatment of tennis elbow is interesting, for an extraordinary number of 
physiotherapeutic and other procedures were advocated for this comparatively trivial condition. This meant, of course, that no truly satisfactory treatment existed. The list of physiotherapeutic procedures included anodal and cathodal galvanism, faradism of the extensor muscles against resistance, deep massage and frictions, all forms of heat, ultrasound waves, various ionizations and local ultraviolet irradiation. If any of these were used towards the end of the natural period of the condition, recovery would occur and a false impression of the treatment's efficacy might be formed in the mind of the doctor or the physiotherapist. Others advocated injection of various analgesic substances into the tender epicondyle; others treated by manipulation. If the patient could be persuaded to persevere, all these treatments could eventually prove effective. In other cases the patient's impatience could take her to the orthopaedic surgeon who could offer operative treatment consisting in separating the extensor origin from the external epicondyle and letting it slide down, or else in ' excising the tender spot.' Such heroic measures are not often called for.

The introduction of hydrocortisone administered by local injection led to a complete change in our approach to golfer's and tennis elbow. It very soon became the treatment of election and has undoubtedly saved a great deal of time and physiotherapy. Essentially the treatment consists of injecting $25 \mathrm{mg}$. of hydrocortisone acetate in solution into the point of maximum tenderness at the epicondyle. Some prefer to inject a little novocain first to anaesthetize the skin and find the point of maximum tenderness with accuracy. The patient should be warned that the pain may be aggravated 24 hours after the injection but will then begin to decrease.

There is no need for concomitant physiotherapy. Sometimes a second or even a third injection is needed. The London Hospital figures for 1957 show for tennis elbow:-

per cent.

Successes with I injection $\quad \ldots \quad 52 \quad 65$

", $\quad$ " 2 injections $\quad \ldots \quad$ I8 22.5

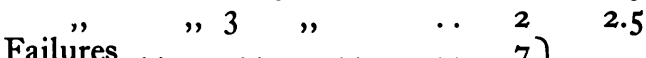

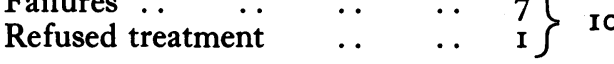

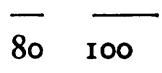

Two of the failures agreed to operation by the orthopaedic surgeons and recovered. The others gradually got better and were symptom-free eventually although one took two years to achieve this. Only one patient refused to be treated by injection.

For golfer's elbow the figures were:-

Successes with I injection $\quad \ldots \quad 5 \quad 56$

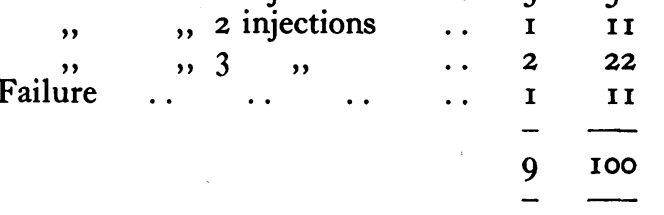

These figures show that the treatment of election of tennis elbow is the injection of hydrocortisone. This treatment does not always succeed, but in most cases it presents a much simpler and quicker means of obtaining relief of symptoms than the old regime of prolonged physiotherapy.

\section{REFERENCE}

MORRIS, H. (1882), Lancet, ii, 133.

\section{RUTHIN CASTLE, NORTH WALES}

A Clinic for the diagnosis and treatment of Internal Diseases (except Mental or Infectious Diseases). The Clinic is provided with a staff of doctors, nurses, technicians, modern Radiological and Physiotherapy departments.

The surroundings are beautiful. The climate is mild. There is central heating throughout. The annual rainfall is $\mathbf{3 0 . 5}$ inches, that is less than the average for England.

The Fees are inclusive and vary according to the room occupied.

For particulars apply to THE SECRETARY, Ruthin Castle, North Wales. 